\title{
Saberes de professores propícios à inclusão dos alunos com necessidades educacionais especiais: condições para sua construção
}

Gislaine Semcovici Nozi*

Celia Regina Vitaliano**

\section{Resumo}

Atitudes favoráveis à inclusão escolar de alunos com necessidades educacionais especiais (NEE) têm sido consideradas por diversos pesquisadores como condição essencial para os professores. Considerando essa questão, é objetivo deste artigo descrever os saberes recomendados pela produção acadêmica para a inclusão escolar, bem como as condiçóes que favorecem a sua aquisiçáo. Para tanto, realizamos uma análise documental em teses e dissertações da área da Educação e Educação Especial, disponíveis no Banco de Teses da Capes, e pesquisa bibliográfica. Os dados coletados foram organizados em categorias. Os resultados indicaram a importância da capacidade do professor de valorizar a diferença e a heterogeneidade, de colocar-se no lugar do outro e ser favorável à Educação Inclusiva. Sobre as condiçôes que favorecem a construção de atitudes positivas, identificaram-se a necessidade de desmitificação do conceito de deficiência e reflexôes sobre suas possibilidades, formação adequada, experiências inclusivas positivas e trabalho colaborativo entre professores especialistas, regentes e demais profissionais envolvidos.

Palavras-chave: Saberes docentes; Produção acadêmica; Educação inclusiva.

* Doutoranda em Educação pela Universidade Estadual de Londrina, Londrina, Paraná, Brasil.

** Professora doutora da Universidade Estadual de Londrina, Londrina, Paraná, Brasil. 


\section{Teachers' promising knowledge to the inclusion of students with special educational needs: conditions for its construction}

\section{Abstract}

Favourable social attitudes toward inclusion of students with educational special needs have been supposed to be an essential condition for teachers. Considering this question, the aim of this paper is to describe knowledges recommended in academic production about school inclusion, as well as the conditions that support their acquisition. Therefore, we performed a documental analysis of theses and dissertations in Education and Special Education, available in the data base of Capes, and bibliographic research. The data collected were organized in categories. The results indicated the importance of the teachers' ability to valorize the difference and the heterogeneity, put themselves in others' place, and be favourable to Inclusive Education. Conditions to the construction of positive attitudes were identified: the need to demythicization of the concept of disability and capacities of the disabled, appropriate teacher training, positive experiences of inclusion, and collaborative work among specialized teachers, teachers responsible for the classes and other professionals involved.

Keywords: Teachers' knowledge; Academic production; Inclusive education.

\section{Introdução}

Estudos que tratam do processo de inclusão dos alunos com necessidades educacionais especiais no ensino regular, de modo geral, apontam que os professores não se sentem preparados para efetivar tal processo (MATOS; MENDES, 2014; TAVARES; SANTOS; FREITAS, 2016; VITALIANO, 2010). Muitos professores relatam que a entrada de tais alunos na sala de aula os fizeram sentir medo e insegurança, associados à dificuldade de ensinar e com eles interagir (MONTEIRO; MANZINI, 2008). Matos e Mendes (2014, p. 27), ao analisarem demandas advindas do processo de inclusão, consideram que os "atores e autores educacionais são desafiados a construir saberes capazes de responder às demandas do cotidiano escolar relacionadas à convivência e aprendizagem na diversidade".

Quando tratamos dos saberes docentes para a inclusão, detectamos que não diferem de forma significativa dos saberes necessários para ensinar alunos sem deficiências, por serem saberes recomendados para qualquer professor que queira atender às necessidades de qualquer aluno, independentemente de suas condições orgânicas, sociais, econômicas, étnicas, culturais, de gênero etc. (NOZI, 2013). Tais saberes se desenvolvem a partir de sua história de vida, formação acadêmica inicial, na carreira profissional docente, bem como influenciados pelos contextos culturais e sociais vividos. Confirma Tardif (2014, p. 21): "o saber dos professores não provém de uma fonte única, mas de várias fontes e de diferentes momentos”. 
Um dos aspectos importantes para a construção de escolas inclusivas é, sem dúvida, a formação dos professores, já que eles são os principais agentes de mudanças (RODRIGUES, 2014). Rodrigues (2008) alerta sobre o fato de que pouco servem aos professores os conhecimentos e competências, se eles não tiverem uma atitude positiva frente à inclusão desses alunos em suas classes. Além do conhecimento científico e instrumental, a docência pressupõe saberes de cunho afetivo, valorativo e ético na composição de seu saber-fazer. Na mesma direção, Tardif e Raymond (2000, p. 213) destacam que as atitudes dos professores estão associadas ao "saber ser", o qual faz parte da essência da funçáo institucional, social e coletiva do professor, estabelecida de acordo com a tradição e cultura ocupacional. Exemplificam como atitudes afins: "[...] gostar de trabalhar com jovens e crianças [...], partir da experiência dos alunos [...], desempenhar o seu papel de forma profissional sem deixar de ser autêntico, ser capaz de questionar a si mesmo". Desse modo, entendemos, assim como Pinheiro (2001), Omote, et al. (2005) e Monteiro e Manzini (2008), que as atitudes dirigem os comportamentos e, caso os professores tenham atitudes positivas frente aos seus alunos com NEE, há maior probabilidade de que desenvolvam práticas pedagógicas de modo a favorecer a inclusão. Caso contrário, poderão apresentar poucas iniciativas nessa direção.

No entanto, as atitudes (que, para alguns pesquisadores, se constituem numa dimensão dos saberes docentes) recebem pouca atenção durante a formação dos professores. É importante investir na discussão desse aspecto, bem como dimensionar caminhos para que possam ser trabalhadas nos diversos espaços de formação, cursos de formação inicial, continuada e/ou em serviço, e sensibilização dos professores para que desenvolvam atitudes positivas sobre a inclusão escolar.

Os estudos existentes que relacionam atitudes docentes e inclusão tiveram como foco de análise as atitudes sociais dos professores, que se orientam por aportes teóricos e metodológicos da Psicologia Social (CHAHINI, 2010; OMOTE et al., 2005; ORRICO, 2011; SILVA, 2008; VIEIRA, 2014).

De acordo com a Psicologia Social, as atitudes sociais são "[...] uma organização duradoura de crenças e cogniçóes em geral, dotada de carga afetiva pró ou contra um objeto social definido, que predispóe a uma ação coerente com as cogniçóes e afetos relativos a este objeto" (RODRIGUES; ASSMAR; JABLONSKI, 2016, p. 108). Explicita ainda que as atitudes sociais são decorrentes de processos de aprendizagem comuns, derivadas de características pessoais de personalidade ou influenciadas por determinantes sociais, e podem ser inconscientes e formarem-se em decorrência de processos cognitivos. Constituem-se de três componentes: (a) o componente cognitivo, (b) o componente afetivo e (c) o componente comportamental. Com relação a estas três dimensóes, Pinheiro (2001, p. 12) considera a "[...] cognitiva como sendo as crenças, informaçóes e cognições referentes a um objecto social; a afectiva diz respeito a sentimentos de aceitação e/ou rejeição e finalmente a comportamental como sendo a predisposição para a acção numa determinada direcção".

De acordo Rodrigues, Assmar e Jablonski (2016, p. 124), as atitudes envolvem o pensamento, o sentimento das pessoas, como elas tendem a se comportar em 
relação a um objeto atitudinal e como "[...] pensam que devem fazer, isto é, normas sociais", e estas, por sua vez, influenciam a relação entre atitudes e comportamentos. Sendo assim, embora as atitudes sejam predisposiçôes duradouras, são passíveis de mudança e, para que ela ocorra, é importante que se observem as condiçóes adequadas (SOUZA; SILVERO; GALHARDI, 2014).

Quando tratamos das atitudes dos professores em relação aos alunos com NEE, não podemos esquecer que, historicamente, esses alunos foram, por um longo tempo, considerados alvos de atendimentos segregados. Avaliavam-se apenas suas limitaçóes, que eram vistas como condiçôes que os impossibilitavam de aprender e participar do ensino comum, assim como, devido à sua aparência e comportamentos, eram considerados "[...] distantes, em maior ou menor grau, dos padrôes que desde cedo aprendemos como desejáveis" (VITALIANO; MANZINI, 2010, p. 71). Dessa forma, quando identificamos a importância de desenvolver atitudes positivas dos professores frente à inclusão desses alunos, é imprescindível lembrar que o processo histórico de atendimento à essa população tem um forte efeito nas atitudes que os professores apresentam frente aos seus alunos com NEE.

Temos ainda outros aspectos a considerar quando nos referimos às atitudes dos professores frente aos alunos com NEE, visto que se manifestam de modos diversos, dependentes tanto de variáveis pessoais do próprio professor como das características apresentadas pelos referidos alunos. Omote et al. (2005, p. 387) evidenciam que "o gênero, a idade cronológica, o tempo de experiência docente no ensino comum, o nível de escolaridade e a experiência no ensino de aluno deficiente [...]” são variáveis que podem estar relacionadas às atitudes dos professores.

Com base em tais análises, este artigo tem como objetivo descrever os saberes atitudinais recomendados pela produção acadêmica para a inclusão escolar, bem como as condiçôes que favorecem a sua aquisição.

\section{Método}

Trata-se de uma pesquisa documental realizada no Banco de Teses da Coordenação de Aperfeiçoamento de Pessoal de Nível Superior (CAPES), incluindo dissertações e teses nas áreas de Educação e Educação Especial, defendidas entre 2005 e 2012, que tratavam de inclusáo de alunos com necessidades educacionais especiais. Adicionalmente, foi feito levantamento bibliográfico no Banco de Periódicos da CAPES, combinando os descritores professores, formação, atitudes, inclusâo, necessidades educacionais elou deficiência.

O material levantado foi analisado e foram identificados extratos de textos sobre saberes dos professores relacionados à temática. A síntese desse material é organizado na forma de categorias, seguindo as orientaçóes de Bardin (2006).

\section{Resultados e discussão}

Foram analisados 140 trabalhos acadêmicos, tendo encontrado 222 frases alusivas a dimensão atitudinal em 64 deles. Essas frases foram organizadas em sete categorias, conforme descrição a seguir. 


\section{Valorizar a diferença e a heterogeneidade, acreditar no potencial dos alunos e estimular o desenvolvimento deles}

A valorização da diferença e da heterogeneidade em sala de aula, a crença de que o aluno pode aprender e o estímulo para o seu desenvolvimento foram apontados por quarenta e um pesquisadores em sessenta e seis frases como uma atitude importante para os professores atuarem na perspectiva inclusiva.

Os relatos ressaltam que a atitude positiva do professor frente à diferença é uma variável significativa para a atuaçáo em contextos educacionais inclusivos com vistas ao combate de qualquer tipo de discriminação e em prol da valorização e do respeito à diversidade humana, influenciando o processo de aprendizagem. Além disso, lidar com a diversidade é uma exigência posta não apenas pela educação inclusiva, mas pela própria configuração do trabalho docente de modo geral.

Os professores, ao assumirem o compromisso de atuar na perspectiva da educação inclusiva, demandarão o aprendizado do acolhimento de diferentes alunos, buscando compreender, enfrentar e superar os estereótipos existentes em relaçáo às minorias, no caso, os alunos com deficiência, procurando nos desafios as perspectivas de uma escola pública, democrática e aberta à diversidade dos alunos, tendo isso como princípio norteador de sua práxis pedagógica (FAITANIN, 2010, p. 15).

Além de atitudes de respeito e valorização das diferenças, os pesquisadores apontam a necessidade de o professor possuir habilidades para trabalhar com a heterogeneidade em sala de aula. Reganhan e Braccialli (2008) avaliaram que a educação inclusiva exige do professor o domínio de recursos e estratégias variadas para o trabalho com a diversidade. Análise semelhante é a de Glat et al. (2006), ao ponderarem que, além de assumir a diversidade de sua sala de aula, o professor precisa saber lidar pedagogicamente com ela.

A heterogeneidade sempre esteve presente em sala de aula, porém, mascarada por procedimentos de ensino padronizados, tendo como modelo o aluno ideal. Nesse sistema, geraçóes de alunos foram expulsas da escola por não se enquadrarem em padrôes pré-estabelecidos de ritmos e níveis de aprendizado.

O trabalho pedagógico pautado na valorização da diferença resgata valores humanos de respeito e solidariedade e princípios ético-profissionais que exigem do professor o compromisso com o desenvolvimento acadêmico e social de todos os seus alunos, imprimindo aos educadores o papel de participantes na luta pela construção de uma escola que, ao invés de excluir, agrega, acolhe, acresce (CORREAA; STAUFFER, 2008).

Disto decorre que a escola inclusiva deve assumir a heterogeneidade como critério positivo e necessário. Para a educaçáo ter sucesso, a diferença não se deve constituir num problema, mas num desafio à capacidade da escola em se modificar de forma a ser capaz de proporcionar uma educação de qualidade a todos os seus alunos (RODRIGUES, 2014). 


\section{Ter responsabilidade pedagógica: compromisso com o desenvolvimento e aprendizagem dos alunos}

Trinta e dois pesquisadores identificados em quarenta e seis frases indicaram ser necessário que os professores assumam o compromisso com o desenvolvimento de todos os alunos, que denominamos de responsabilidade pedagógica.

Identificamos nos textos a defesa de que a responsabilidade pedagógica do professor está atrelada à sua função social, ou seja, disseminação e mediação dos conhecimentos científicos, sistematizados, historicamente construídos.

O foco da escola é o aluno e sua aprendizagem. A escola é o espaço constituído, significado e reconhecido socialmente, como espaço favorecedor da aprendizagem. Os profissionais que nelas estâo, precisam se apropriar deste foco, principalmente quando se trata de uma escola inclusiva, onde os alunos têm o direito de ter acesso a todas as gamas de oportunidades educacionais e sociais oferecidas pela escola (SANTANA, 2010, p. 214).

Contudo, a responsabilidade pelo desenvolvimento do aluno não é exclusiva do professor, precisa ser compartilhada pelos demais profissionais da escola (TORRES, 2009). Como exemplo, poderíamos citar o fato de que é comum encontrarmos relatos na literatura de que o trabalho pedagógico com alunos deficientes ainda tem ficado a cargo dos professores especializados durante os atendimentos educacionais especializados. Paira, nesses contextos, a concepção errônea de que a inclusão serve apenas para a socialização dos alunos, não valorizando a aprendizagem de conteúdos escolares.

A função social da escola consiste em propiciar aos alunos o acesso aos conhecimentos científicos, à cultura letrada, ao saber sistematizado e "criar possibilidades para a produção ou construçáo do conhecimento" (FREIRE, 1996, p. 47), independentemente das condiçóes físicas, biológicas, econômicas, culturais e sociais dos sujeitos que a frequentam. Neste sentido, Alves (2010) e Torres (2009) entendem que o professor não precisa assumir funçôes que não são suas. Precisa saber, todavia, quais são de sua responsabilidade e fazer o possível para colocá-las em prática, contando com os recursos necessários para a realização do seu trabalho.

\section{Dispor-se a ressignificar conceitos e práticas}

Vinte e nove pesquisadores citaram, em quarenta e seis frases, que os professores que atuam na perspectiva educacional inclusiva se disponham a ressignificar conceitos e práticas cristalizadas, muitas vezes fundamentadas em concepçôes errôneas sobre as pessoas deficientes, suas possibilidades e limitaçôes. Conforme expressa o trecho que segue:

Ao considerar que a inclusão trouxe benefícios e melhorias na qualidade de ensino, entende-se que a escola deve se modificar e ser repensada, onde professores repensem suas práticas, suas atitudes, crenças e valores e, principalmente suas metodologias e recursos didáticos voltados para o atendimento à diferença e às especificidades de cada educando, inclusive aqueles que apresentam dificuldades, necessidades e deficiências (COELHO, 2008, p. 82). 
Não é apenas para os alunos com NEE que são exigidas posturas e práticas diferentes por parte dos professores. Todos os alunos precisam contar com posturas diferenciadas do professor. Quando existirem especificidades no processo de aprender, mudanças são necessárias no modo de ensinar.

De modo geral, os pesquisadores apontaram a necessidade de que o professor deixe de lado concepçôes e práticas homogeneizadoras, que tentam encaixar os alunos em modelos pré-estabelecidos de desenvolvimento e aprendizagem. A prática educacional inclusiva tem como pressuposto que as pessoas aprendem de modo e em ritmos diferentes e que, portanto, precisam de métodos diversificados para poder aprender, já que não é só o aluno que deve se adequar à organizaçáo escolar, mas a escola também deve rever-se para atender às necessidades dos alunos.

\section{Dispor-se a estar em processo permanente de formação continuada ou em serviço}

Vinte e seis pesquisadores avaliaram, em trinta e nove frases, ser fundamental que os professores estejam dispostos a estar em processo de formação constante, em formação continuada ou em serviço, para que aprimorem suas possibilidades de atuação junto aos alunos com NEE. Alves (2010, p. 100) considera que:

Não se pode deixar de enfatizar a responsabilidade do professor pela sua própria formaçáo. O professor precisa reconhecer a importância de se capacitar melhor e buscar meios para seu aprimoramento profissional. Sabe-se que a educação inclusiva é hoje um desafio a ser superado e que o poder público tem uma grande responsabilidade nesse processo. Por outro lado, os professores náo podem ignorar essa realidade e precisam se informar melhor sobre essa temática, pois trata-se de uma temática que faz parte de sua atuação profissional.

Sabemos que é inerente ao magistério, como a qualquer outra profissão, a necessidade de leitura e aperfeiçoamento constantes devido às rápidas mudanças no campo político, econômico e cultural, que interferem no que se ensina em sala de aula. Porém, entendemos que náo deve ficar a cargo somente dos professores o investimento. Há custo financeiro por uma formação específica que os prepare para o atendimento aos alunos com NEE, e é de responsabilidade dos sistemas de ensino propiciar açóes formativas aos professores que estão em serviço, o estado não pode ser isento de tal responsabilidade.

Exemplos de como pode ocorrer o processo de formação continuada são dados:

A autoformação é uma necessidade do professor pois, por meio dela, poderá conhecer novas teorias que lhe permitirão melhorar sua atuação, mas é necessário que haja um espaço na escola, para que aconteçam, sistematicamente, encontros, estudos e discussóes com os professores sobre a prática pedagógica que desenvolvem diariamente (SANTOS, 2007, p. 99). 
O professor deve estar sempre preparado, em constante formação e aperfeiçoamento, mediante os cursos, pós-graduação, encontros/ seminários, congressos, etc. (OLIVEIRA, 2007, p. 14).

Observamos maior ênfase na formação continuada ou em serviço para o atendimento aos alunos com NEE. Imaginamos que tais indicaçóes se concentram nesses espaços de formação pela constatação da carência de formação específica nos cursos de formação inicial.

Conforme Silva (2008), a formação continuada é um espaço extremamente importante por ser onde acontece a atualização dos profissionais que estâo no exercício de suas funções docentes. A formação inicial deve ser repensada para que os profissionais, ao saírem das universidades, não fiquem à mercê apenas de cursos de formaçáo pontuais para o atendimento dos alunos com NEE, mas tenham condiçóes mínimas de realizar os procedimentos necessários no processo de ensino-aprendizagem dos alunos com NEE.

\section{Dispor-se à alteridade}

Seis autores comentaram, em sete parágrafos, sobre a importância de os professores se disporem a se colocar no lugar do outro, especificamente de seus alunos. Seguem recortes que contemplam essa indicação:

Em face de tal conjectura, certo nos parece, que incluir exige que o professor além da condição de quem ensina se ponha no lugar de quem aprende (DUEK, 2006, p. 157).

A açáo profissional do educador, pautada no respeito aos direitos humanos como dimensão ética, deve ter a capacidade de realizar um movimento de saída de si ao encontro do outro. É na busca do diálogo com o outro que será possível o entendimento dos direitos e uma intervenção humana (MATOS, 2008, p. 65).

Observamos nos relatos, que os pesquisadores consideram a capacidade de o professor se colocar no lugar do outro nas relaçóes interpessoais como um fator preponderante para a efetivação de processos educacionais inclusivos, assim como observaram Omote et al. (2005) e Sant' Ana (2005).

Duek (2007, s.p.) afirma que "a inclusão tem a ver com a postura que o professor assume frente ao que lhe é estranho, desconhecido, no caso da deficiência, isso irá depender de como o educador percebe a diferença do outro". A autora expóe que o que está em jogo na inclusão é o "[...] olhar lançado pelo professor sobre a deficiência/diferença do outro, sem que isso implique em negá-la”. Para ela, é necessário que o professor consiga enxergar o outro para além da sua deficiência, vislumbrando uma pessoa dotada de capacidades e potencialidades, "[...] ao invés de ater-se à sua limitação, à sua dificuldade”.

\section{Ser favorável à educação inclusiva}

O posicionamento favorável à educação inclusiva foi comentado por seis pesquisadores. Observam-se exemplos a seguir: 
[...] os professores devam envolver-se ideologicamente com a proposta inclusiva sob o risco de se tornarem profissionais que realizam tarefas sem, contudo, refletir sobre as implicaçóes desta proposta (PEREIRA JR, 2009, p. 102).

[...] além das questôes humanas e estruturais, o professor deve estar sensível a esta causa e abraçar o ensino inclusivo para que, de fato, ele aconteça (ROCHA, 2007, p. 22).

Pesquisadores, como Omote et al. (2005), têm apontado que a atitude em prol da inclusão é um dos fatores determinantes para o sucesso de tal proposta. Acreditamos que o posicionamento em prol ou contra a inclusão não é estático, uma vez que os professores estão em constante processo de ressignificação e construçáo de sua identidade pessoal e profissional e processos de formação podem ser implementados para favorecer a construção de atitudes positivas em relação ao trabalho com alunos com NEE.

\section{Dispor-se a buscar apoio}

Um pesquisador apontou ser necessário que o professor que atua na Educação Inclusiva tenha a disposição de buscar apoio para incluir seus alunos com NEE. Damasceno (2006, p. 10) ressaltou que:

$$
\begin{aligned}
& \text { [...] o professor precisará ser capaz de, por si mesmo, buscar o } \\
& \text { apoio na experimentaçáo, nos diálogos com os pares, nas pesqui- } \\
& \text { sas das Universidades para o enfrentamento das condiçōes adver- } \\
& \text { sas que venha encontrar na estruturação/organização de sua escola } \\
& \text { com proposta inclusiva. }
\end{aligned}
$$

Essa disponibilidade de procurar apoio para a superação de suas dificuldades depende também do conhecimento que o professor tem sobre os pressupostos legais que fundamentam a Educação Inclusiva, porque, para pedir ajuda, ele tem que saber quem pode lhe dar suporte para sua atuação.

Nem sempre os professores encontram na própria escola o apoio necessário para a minimização de suas dificuldades. Neste sentido, ao conhecer a especificidade do trabalho dos especialistas no processo educacional inclusivo e reconhecendo que eles possuem uma gama de conhecimentos acumulados sobre as especificidades da educação das pessoas com NEE, é importante o professor tentar estabelecer parceria com esses profissionais para o aprimoramento de seu trabalho, visto que os especialistas em Educação Especial podem contribuir de forma significativa para o processo de inclusão de alunos com NEE.

\section{Condições para a construção de atitudes positivas dos professores em relação à inclusão dos alunos com NEE}

É importante que o professor desenvolva atitudes positivas frente ao processo de inclusão. Em algumas das categorias descritas, foi identificada a importância do processo de formação. Outras remetem às iniciativas pessoais, ligadas à disposição pessoal e crença de auto-eficácia. Apontam-se também condiçóes de trabalho existentes. 
Sobre a formação dos professores, iniciamos com a premissa de que é de suma importância possibilitar a eles maior consciência dos determinantes de suas atitudes frente aos alunos com NEE, as quais provavelmente são atreladas aos padrôes sociais de classificação e estigmatizaçáo dos indivíduos que se desviam das normas (ROSSATO; LEONARDO, 2012). A sua conscientização pode permitir que o professor possa desmitificar o conceito de deficiência e de anormalidade e passe a compreender que os alunos com NEE, associadas à condiçáo de deficiência, têm suas possibilidades de desenvolvimento e aprendizagem a serem exploradas.

Quando falamos sobre formação de professores, entendemos que ela não deve ser apenas o acúmulo de cursos, é necessário que os conteúdos sejam trabalhados de modo significativo e aliados às necessidades cotidianas, para que possam ser aplicados e ser objeto de reflexáo. $\mathrm{O}$ processo de reflexão e ação com base em suas experiências de sala de aula e dos conhecimentos científicos adquiridos enriquece e qualifica o trabalho pedagógico, sendo relevante que os professores tenham apoio para esclarecer suas dúvidas (NÓVOA, 1992; SIMÃO; CAETANO; FLORES, 2005).

Considerando que as atitudes envolvem aspectos cognitivos, afetivos e comportamentais, recomenda-se que o processo de formação explore essas três dimensôes com conhecimentos teóricos, vivências, sensibilizaçôes, estudos de casos, análises de vídeos e experiências diretas com pessoas com deficiência (OMOTE, et al. 2005; RODRIGUES, 2008). Além disso, é importante que o processo de formação seja ministrado por pessoas hábeis e experientes no atendimento de alunos com NEE e por um período que possibilite aos participantes refletirem sobre os conhecimentos, porque cursos de curta duraçáo podem não favorecer o processo reflexivo necessário ao desenvolvimento das mudanças de atitudes esperadas (SIMÃO; CAETANO; FLORES, 2005).

Outro aspecto a ser cuidado refere-se à gravidade dos casos a serem estudados. Como apenas uma porcentagem mínima de alunos é mais comprometida, as discussóes dos casos devem se referir aos mais frequentes encontrados na escola, para se evitar que a crença de que os alunos com NEE são incapazes de aprender seja reforçada (RODRIGUES, 2008).

Em relaçáo ao contexto de trabalho do professor, sabe-se que quanto mais apoio, orientaçôes e materiais didáticos adequados ao atendimento das necessidades educacionais especiais the sejam acessíveis, mais facilidade irá encontrar para lidar com seus medos e inseguranças e perceber as potencialidades de aprendizagem que seus alunos apresentam. Para dispor de tais condiçôes, muitos pesquisadores indicam o modelo de trabalho colaborativo, no qual a comunidade escolar adota o processo de inclusão como objetivo e passa a atuar em um sistema integrado de colaboração mútua, incluindo professores da classe comum, professores especialistas em Educação Especial, os próprios alunos, gestores e familiares (DÍEZ, 2010).

A respeito das variáveis pessoais do professor, damos destaque à crença de auto-eficácia. Bzuneck (2000) identificou que: a) as crenças de auto eficácia estão relacionadas com o comprometimento do professor com o ensino: quanto maior a 
percepção de auto-eficácia, mais comprometido e competente ele é; b) professores que apresentam crenças mais altas de auto-eficácia têm maior disposição em adotar práticas pedagógicas inovadoras; c) professores com alta crença na sua eficácia para o ensino tendem a considerar que as dificuldades de aprendizagem e comportamento de seus alunos podem ser remediados por meio de açôes pedagógicas que dependem deles mesmo e não de fatores externos ou de outras pessoas; d) professores que se sentem auto-eficazes obtêm maior progresso no trabalho com alunos com dificuldades de aprendizagem, além de construírem um ambiente favorável para a aprendizagem; e) os alunos são altamente influenciados pela crença de eficácia de seus professores. Para aumentar a percepção de auto-eficácia docente, devemos oferecer modelos efetivos de como ensinar (FERREIRA, 2014).

\section{Considerações finais}

As atitudes dos professores para favorecer a inclusão estão relacionadas às suas características pessoais que, por não serem estáticas, podem ser influenciadas pelos processos formativos a que têm acesso, bem como pelas condiçóes de trabalho que lhes são dadas. Visto que as atitudes são determinantes no comportamento, é importante que as instâncias formativas se preocupem com os conteúdos e as estratégias que possam favorecer o desenvolvimento das atitudes favoráveis à inclusão. Considerando que muitas vezes o desenvolvimento da dimensão atitudinal dos docentes, apesar de ser considerada uma importante variável que interfere em seus comportamentos, não se constitui em alvo de processos formativos, alertamos que esta lacuna pode dificultar a efetividade do processo.

De modo geral, os resultados deste estudo evidenciam que, para que o professor apresente saberes atitudinais que favoreçam a inclusão escolar de alunos com NEE e se comprometa com a aprendizagem e desenvolvimento de seus alunos, deve colocar-se no lugar deles; buscar por formação e apoio; refletir sobre os seus conceitos e esforçar-se para ressignificá-los. Para isto, é importante que ele tenha acesso a conhecimentos que lhe permitam a desmitificação do conceito de deficiência e reflexôes sobre suas possibilidades, formaçáo adequada, experiências inclusivas positivas, trabalho colaborativo com os professores especialistas e demais profissionais envolvidos. Acreditamos que, se propiciadas estas condiçôes, o professor poderá sentir-se mais seguro e capacitado para ensinar os alunos com NEE e mais predisposto a desenvolver os saberes atitudinais recomendados para a inclusão.

\section{Referências}

ALVES, M. J. de M. A educaçáo inclusiva nas escolas públicas municipais de Anápolis nos anos iniciais do ensino fundamental e a formaçáo docente. 2010. 125 f. Dissertaçáo (Mestrado em Educaçáo) - Centro Universitário de Anápolis, Pontifícia Universidade Católica de Goiás, Anápolis, GO. 2010.

BARDIN, L. Análise de conteúdo. 3. ed. Lisboa: Ediçôes 70, 2006.

BZUNECK, J. A. As crenças de auto-eficácia dos professores. In: SISTO, F. F.; OLIVEIRA, G. de C.; FINI, L. D.T. (Org.). Leituras de psicologia para formação de professores. Petrópolis, RJ: Vozes, 2000. p. 115134. Disponível em: <http://leg.est.ufpr.br/lib/exe/fetch.php/projetos:educacao:bzuneck1.pdf>. Acesso em: 07 maio 2017.

CHAHINI, T. H. C. Atitudes sociais e opinióes de professores e alunos da Universidade Federal do Maranhão em relaçáo à inclusáo de alunos com deficiência na Educaçáo Superior. 2010. 132 f. Tese (Doutorado em Educação) - Faculdade de Filosofia e Ciências, Universidade Estadual Paulista - Unesp, Marília, SP, 2010. 
COELHO, W. L. R. Política maranhense de inclusáo escolar: com a palavra, as professoras. 2008. Dissertação (Mestrado em Educação) - Universidade Federal do Maranhão, São Luis, 2008.

CORRÊA, V. L. A. dos S.; STAUFFER, A de B. Educação Inclusiva: repensando políticas, culturas e práticas na escola pública. In: SANTOS, M. P dos; PAULINO, M. M. (Org.). Inclusáo em educaçáo: culturas, políticas e práticas. São Paulo: Cortez, 2008. p.123-142.

DAMASCENO, A. R. A formaçáo de professores e os desafios para a educaçáo inclusiva: as experiências da Escola Municipal Leônidas Sobrino Pôrto. 2006. 190 f. Dissertação (Mestrado em Educação) - Universidade Federal Fluminense, Niterói, 2006.

DÍEZ, A. M. Traçando os mesmos caminhos para o desenvolvimento de uma educação inclusiva. Inclusão: R. Educ. Esp., Brasília, DF, v. 5, n. 1, p. 16-25, jan./jul. 2010. Disponível em: <http://www.ufsm.br/revistaeducacaoespecial>. Acesso em: 20 fev. 2017.

DUEK, V. P. Docência e inclusão: reflexóes sobre a experiência de ser professor no contexto da escola inclusiva. 2006. 186 f. Dissertação (Mestrado em Educação) - Universidade Federal de Santa Maria, Santa Maria, RS, 2006.

Um olhar sobre a deficiência/diferença na escola inclusiva. Rev.Cent. de Educ., Cadernos, n. $29,2007$. Disponível em: <http://coralx.ufsm.br/revce/ceesp/2007/01/r3.htm>. Acesso em: 10 maio 2017.

FAITANIN, G. P. da S. Formação e educaçáo inclusiva: as concepçóes do curso de pedagogia. 2010.151 f. Dissertação (Mestrado em Educação) - Universidade Federal Fluminense, Niterói, 2010.

FERREIRA, Luiza Cristina Mauad. Crenças de autoeficácia docente, satisfação com o trabalho e adoecimento. Psicol. Ensino \& Form., Brasília, DF, v. 5, n. 2, p. 19-37, 2014. Disponível em: <http://pepsic.bvsalud.org/ pdf/pef/v5n2/v5n2a03.pdf>. Acesso em: 07 maio 2017.

FREIRE, P. Pedagogia da autonomia: saberes necessários à prática educativa. 34. ed. São Paulo: Paz e Terra, 1996. $148 \mathrm{p}$.

GLAT, R. et al. Formação de professores na educação inclusiva: diretrizes políticas e resultados de pesquisas. In: ENDIPE - ENCONTRO NACIONAL DE DIDÁTICA E PRÁTICA DE ENSINO, 13., 2006, Recife. Anais... Recife, 2006. Disponível em: <http://www.eduinclusivapesq-uerj.pro.br/livros_artigos/pdf/endipe3. pdf>. Acesso em: 01 maio 2017.

MATOS, M. A. de S. Cidadania, diversidade e educação inclusiva: um diálogo entre a teoria e a prática na rede pública municipal de Manaus. 2008. 229 f. Tese (Doutorado em Educação) - Faculdade de Educação, Universidade Federal do Rio Grande do Sul, Porto Alegre, 2008.

MATOS, S. N.; MENDES, E. G. Demandas decorrentes da inclusão escolar. Revista Educaçáo Especial, Santa Maria, RS, v. 27, n. 48, p. 27-40, jan./abr. 2014. Disponível em: <https://periodicos.ufsm.br/educacaoespecial/article/view/8796/pdf>. Acesso em: 10 maio 2017.

MONTEIRO, A. P. H.; MANZINI, E. J. Mudanças nas concepçóes do professor do ensino fundamental em relação à inclusão após a entrada de alunos com deficiência em sua classe. Rev. Bras. Ed. Esp., Marília, SP, v. 14, n. 1, p. 35-52, jan.abr. 2008. Disponível em: <http://www.scielo.br/pdf/rbee/v14n1/a04v14n1.pdf>. Acesso em: 10 maio 2017.

NÓVOA, A. Os professores e a sua formação. Lisboa: Dom Quixote, 1992.

NOZI, Gislaine Semcovici. Análise dos saberes docentes recomendados pela produçáo acadêmica para a inclusáo escolar de alunos com necessidades educacionais especiais. 2013. 180 f. Dissertação (Mestrado em Educação) Universidade Estadual de Londrina, Londrina, PR, 2013.

OLIVEIRA, K. B. de. Educação Inclusiva e Formação de Professores no Alto Juruá. Dissertação (Mestrado em Educação) - Faculdade de Educação. 2007. 124 f. Universidade Federal do Amazonas, Manaus, 2007.

OMOTE, S. et al. Mudança de atitudes sociais em relação à inclusão. Paidéia, Ribeirão Preto, v. 15, n. 32, p. 387-398, dez. 2005. Disponível em: <http:/www.scielo.br/pdf/paideia/v15n32/08.pdf>. Acesso em: 05 maio 2017.

ORRICO, H. F. A inclusáo educacional de alunos com necessidades educativas especiais frente ao aspecto atitudinal do corpo docente nos primeiros e sextos anos do Ensino Fundamental. 2011. 114 f. Tese (Doutorado em Educação) - Faculdade de Filosofia e Ciências, Universidade Estadual Paulista, Marília, SP, 2011.

PEREIRA JR, A. A. Atitudes Sociais de Professores da Rede de Ensino Municipal de Guarapuava/PR em Relaçáo à Educaçáo Inclusiva. 2009. 120 f. Dissertação (Mestrado em Educação). Universidade Estadual Paulista - Unesp, Marília. 2009. 
PINHEIRO, I. de F. A. Atitudes dos professores do $2^{\circ}$ ciclo do ensino básico das escolas do CAE - Tâmega face à inclusáo de alunos com deficiência. 2001. 161 f. Dissertação (Mestrado em Educação) - Universidade do Porto: Faculdade de Ciências do Desporto e de Educaçáo Física, 2001.

REGANHAN, W. G.; BRACCIALLI, L. M. P. Inserção de alunos com deficiência no ensino regular: perfil da cidade de Marília. Rev. bras. educ. esp., Marília, SP, v. 14, n. 3, dez-2008. Disponível em: <http://www.scielo. br/pdf/rbee/v14n3/v14n3a05.pdf>. Acesso em: 28 abr. 2017.

ROCHA, Leonor Paniago. Estudo sobre a implantaçáo do "Projeto Escola Inclusiva" em uma escola de ensino fundamental do interior de Goiás. 2007. 163 f. Dissertação (Mestrado em Educação) - Faculdade de Ciências e Letras Julio de Mesquita Filho da Universidade Estadual Paulista, Campus de Araraquara, 2007.

RODRIGUES, D. Desenvolver a Educação Inclusiva: dimensões do desenvolvimento profissional. Inclusão: Rev. Educ. Esp., Brasília, DF, v. 4, n. 2, p. 7-16, jul./out. 2008. Disponível em: <http://portal.mec.gov.br/ index.php?option=com_docman\&view=download\&alias=401-revista-inclusao-n-6\&category_slug=documentos-pdf\&Itemid=30192>. Acesso em: 01 maio 2017.

Os desafios da equidade e da inclusão na formação de professores. Revista Nacional e Internacional de Educación Inclusiva, v. 7, n. 2. p. 5-21. jun. 2014. Disponível em: <http://revistaeducacioninclusiva.es/index. php/REI/article/view/140/134>. Acesso em: 02 maio 2017.

RODRIGUES, A.; ASSMAR, E. M. L.; JABLONSKI, B. Psicologia Social. Petrópolis, RJ: Vozes, 2016. (Manuais Acadêmicos).

ROSSATO, S. P. M.; LEONARDO, N. S. T. Concepçóes de deficiência intelectual e educação especial desnaturalizaçôes necessárias. In: RIBEIRO, M. J. L. (Org.). Educaçáo Especial e Inclusiva: teoria e prática sobre o atendimento à pessoa com necessidades especiais. Maringá, PR: EDUEM, 2012. p. 73-84.

SANT'ANA, I. M. Educação inclusiva: concepçôes de professores e diretores. Psicologia em Estudo, Maringá, PR, v. 10, n. 2, p. 227-234, ago. 2005. Disponível em: <http://www.scielo.br/pdf/pe/v10n2/v10n2a09.pdf>. Acesso em: 07 maio 2017.

SANTANA, R. S. de. Ressignificaçáo da prática pedagógica: aprendizagem do número numa perspectiva inclusiva. 2010. 227 f. Dissertação (Mestrado em Educaçáo) - Faculdade de Educação, Universidade de Brasília, Brasília, DF, 2010

SANTOS, C. A. de O. Deficiência mental: uma possibilidade de compreensão dos saberes de professores do ensino regular. 2007. 143 f. Dissertação (Mestrado em Educação) - Universidade Federal de Uberlândia, Uberlândia, MG, 2007

SILVA, E. G. O perfil docente para a educaçáo inclusiva: uma análise das atitudes, habilidades sociais e o perfil escolar inclusivo. 2008. 132 f. Tese (Doutorado em Educação) - Faculdade de Filosofia e Ciências, Universidade Estadual Paulista - Unesp, Marília, SP, 2008.

SIMÃO, A. M. V.; CAETANO, A. P.; FLORES, M. A. Contextos e processos de mudança dos professores: uma proposta de modelo. Educaçáo \& Sociedade, Campinas, SP, v. 26, n. 90, jan./abr. 2005, p. 173-188. Disponível em: <http://www.scielo.br/pdf/es/v26n90/a08v2690>. Acesso em: 30 fev. 2017.

SOUZA, M. M. G. da S. de; SILVERO, A. S.; GALHARDI, C. M. Formaçấo inclusiva: concepçôes de deficiência e atitudes sociais em relaçáo à inclusáo de estudantes de Psicopedagogia. Revista Tecer, Belo Horizonte, v. 7, n. 13, p. 79-90, nov. 2014. Disponível em: <http://www3.izabelahendrix.edu.br/ojs/index.php/tec/article/ view/698/619>. Acesso em: 10 maio 2017.

TARDIF, M; RAYMOND, D. Saberes, tempo e aprendizagem do trabalho no magistério. Educaçáo \& Sociedade, Campinas, SP, v. 21, n. 73, p. 209-244, dez. 2000. Disponível em: <http://www.scielo.br/pdf/es/ v21n73/4214.pdf>. Acesso em: 02 maio 2017.

TARDIF, M. Saberes docentes e formação profissional. 17. ed. Petrópolis, RJ: Vozes, 2014. 323 p.

TAVARES, L. M. F. L.; SANTOS, L. M. M. dos; FREITAS, M. N. C. A Educação Inclusiva: um estudo sobre a formação docente. Rev. Bras. Ed. Esp., Marília, SP, v. 22, n. 4, p. 527-542, out. /dez. 2016. Disponível em: <http://www.scielo.br/pdf/rbee/v22n4/1413-6538-rbee-22-04-0527.pdf>. Acesso em: 20 abr. 2017.

TORRES, M. P. Políticas de educaçáo e formaçáo de professores: experiências de inclusăo no município de São Gonçalo/RJ. 2009. 117 f. Dissertação (Mestrado em Educação) - Universidade Federal Fluminense, Niterói, 2009.

VIEIRA, C. M. Atitudes sociais em relaçáo à inclusáo: efeitos da capacitaçấo de professores para ministrar programa informativo aos alunos. 2014. 183 f. Tese (Doutorado em Educação) - Universidade Estadual Paulista, Faculdade de Filosofia e Ciências. Marília, SP, 2014.

Revista Educação Especial | v. 30 | n. 59 | p. 589-602 | set./dez. 2017

Santa Maria 
VITALIANO, C. R. Formaçáo de professores para inclusão de alunos com necessidades educacionais especiais. Londrina, PR: EDUEL, 2010. 164 p.

VITALIANO, C. R.; MANZINI, E. J. A formação inicial de professores para inclusão de alunos com necessidades educacionais especiais. In: VITALIANO, C. R. Formaçáo de professores para inclusão de alunos com necessidades educacionais especiais. Londrina, PR: EDUEL, 2010. p. 49-112.

\section{Correspondência}

Celia Regina Vitaliano - Universidade Estadual de Londrina, Centro de Educação Comunicação e Artes, Departamento de Educação. Campus Universitário - Rodovia Celso Garcia Cid Pr 445 Km 380. Campus universitário. CEP: 86051990. Londrina, Paraná, Brasil.

E-mail: nozigislaine2@hotmail.com - reginavitaliano@gmail.com

Recebido em 11 de julho de 2017

Aprovado em 11 de agosto de 2017 